\title{
A Gene for Congenital Generalized Lipodystrophy Maps to Human Chromosome 9q34
}

\author{
ABHIMANYU GARG, ROSS WILSON, ROBERT BARNES, ELIF ARIOGLU, ZOHRA ZAIDI, FIGEN \\ GURAKAN, NURTEN KOCAK, STEPHEN O'RAHILLY, SIMEON I. TAYLOR, SHAILENDRA B. \\ PATEL $\uparrow$, and ANNE M. BOWCOCK†.
}

Department of Internal Medicine (A.G., R.W., R.B., S.B.P., A.M.B). and Center for Human Nutrition (A.G., S.B.P.), University of Texas Southwestern Medical Center at Dallas, 5323 Harry Hines Boulevard, Dallas, Texas 75235; Diabetes Branch, National Institute of Diabetes and Digestive and Kidney Diseases (E.A., S.I.T.), Bethesda, Maryland 20892; Department of Dermatology (Z.Z.), Zinnah Postgraduate Medical Center, Karachi, Pakistan; The Gastroenterology Unit, Department of Pediatrics (F.G., N.K.), Hacettepe University Faculty of Medicine, Ankara 06100, Turkey; Departments of Medicine and Clinical Biochemistry (S.O.), University of Cambridge, Cambridge CB2 2QR, United Kingdom

\begin{abstract}
Congenital generalized lipodystrophy (CGL, Berardinelli-Seip Syndrome, OMIM \# 269700) is a rare autosomal recessive disorder characterized by near complete absence of adipose tissue from birth. Affected individuals have marked insulin resistance, hypertriglyceridemia and acanthosis nigricans, and develop diabetes mellitus during teenage years. The genetic defect for CGL is unknown. A semi-automated genome-wide scan with a set of highly polymorphic short tandem repeats (STR) was carried out in 17 well-characterized pedigrees and identified a locus for CGL to chromosome 9q34. The maximum two-point lod score obtained was 3.6 at $D 9 S 1818\left(\theta_{\max }=0.05\right)$. There was evidence for genetic heterogeneity $(\alpha=0.73)$ and 2 of the pedigrees were unlinked. Multipoint linkage analysis excluding the 2 unlinked families yielded a peak lod score of 5.4 between loci $D 9 S 1818$ and $D 9 S 1826$. The CGL1 critical region harbors a plausible candidate gene encoding the retinoid X receptor $\alpha(R X R A)$ that plays a central role in adipocyte differentiation. Identification of the CGL gene(s) will contribute to our understanding of the adipocyte differentiation and elucidation of the mechanisms of insulin resistance in disorders of adipose tissue.
\end{abstract}

Near total lack of body fat and marked muscularity from birth are hallmarks of the patients with CGL (Fig. 1) $(1,2)$. Patients have marked insulin resistance, severe hyperinsulinemia, hypertriglyceridemia and low levels of highdensity lipoprotein cholesterol (3). Abnormal glucose tolerance and diabetes mellitus appear usually during or after puberty (3-6). Serum leptin concentrations are markedly low (5). Affected individuals show accelerated growth, voracious appetite, increased metabolic rate and advanced bone age during early childhood $(3,7)$. Umbilical hernia seems to be a consistent finding (3-5). Widespread acanthosis nigricans usually appears later (3). Other clinical features include hepatosplenomegaly and slight enlargement of the hands, feet and mandible, resulting in an "acromegaloid appearance". Affected women may have clitoromegaly, hirsutism, oligoamenorrhea and polycystic ovaries. Successful pregnancy is rare. Affected males, however, have normal reproductive potential. After puberty, focal lytic lesions may appear in the appendicular bones $(7,8)$. Hypertrophic cardiomyopathy has been reported in a few patients (9). Fatty infiltration of the

Address all correspondence and request for reprints to Drs. Abhimanyu Garg (e-mail: agarg@mednet.swmed.edu) or Anne M. Bowcock (e-mail: bowcock@genetics.wustl.edu).

†Current Addresses: Department of Genetics (A.M.B.), Washington University School of Medicine, St. Louis, Missouri 63110; Division of Endocrinology, Diabetes and Medical Genetics (S.B.P.), Medical University of South Carolina, Charleston, South Carolina 29425. liver occurs early and may lead to cirrhosis and its complications $(10,11)$.

Whole body magnetic resonance imaging (MRI) as well as autopsy findings revealed a near complete absence of metabolically-active adipose tissue from subcutaneous areas, intraabdominal and intrathoracic regions, and bone marrow in CGL $(4,11)$. In contrast, normal amounts of mechanical adipose tissue were present in the orbits, palms, soles, scalp, perineum and peri-articular regions. These findings have led us to propose that the gene defect in CGL interferes selectively with growth and differentiation of metabolicallyactive adipose tissue (4) and could result from either agenesis of preadipocytes, failure of preadipocytes to differentiate into mature adipocytes, or failure of mature adipocytes to synthesize and/or store triglycerides.

Previous studies, using a candidate gene approach, excluded several genes involved in insulin action, lipid metabolism and adipocyte biology (12-16). However, many other genes involved in adipocyte differentiation, such as CCAAT/enhancer binding proteins (C/EBP) $\alpha, \beta$ and $\delta$, peroxisome proliferator-activated receptor $\gamma$ (PPAR $\gamma$ ), retinoid $\mathrm{X}$ receptor $\alpha(\mathrm{RXR} \alpha)$, sterol responsive element-binding protein 1 (SREBP1), and preadipocyte factor-1 (Pref-1), adipsin, glucose transporter- 4 and tumor necrosis factor- $\alpha$ remain as potential candidate genes. Recent reports of 2 transgenic mice exhibiting many features of CGL suggest that altered expression of transcription factors, such as SREBP1c and $\mathrm{C} / \mathrm{EBP}$ may be involved in the pathogenesis of CGL 
$(17,18)$. We adopted a linkage analysis approach to localize the gene/s altered in CGL.
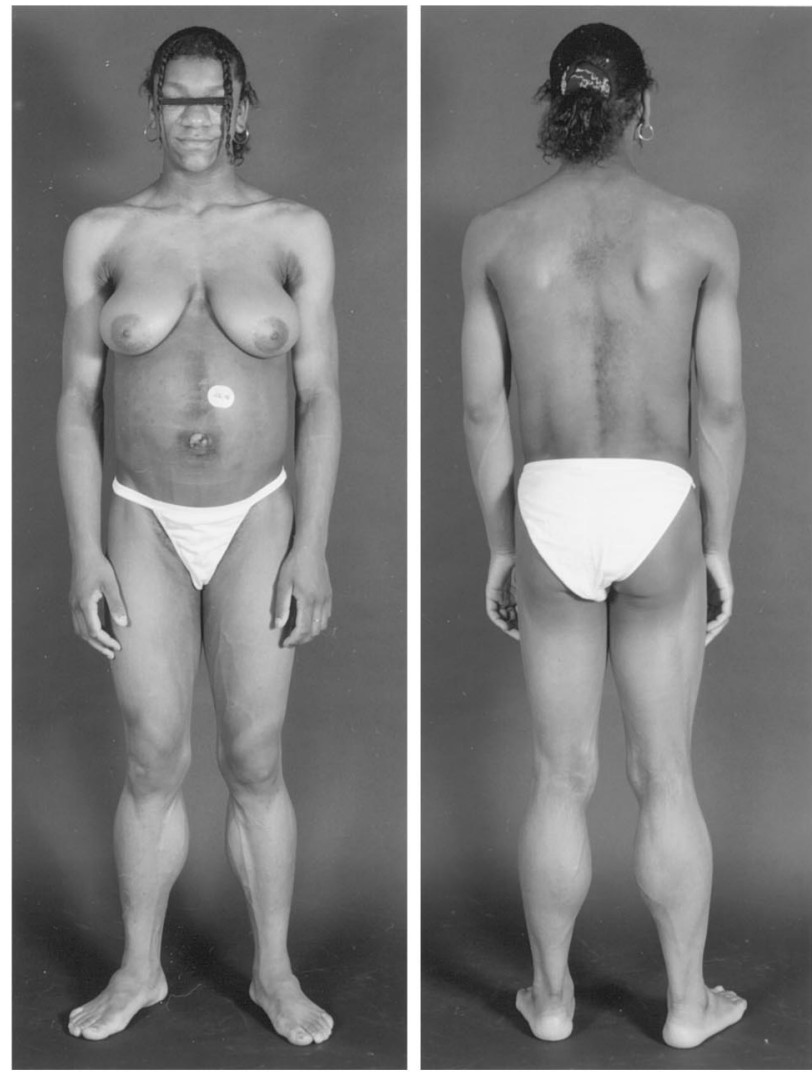

Fig. 1. Clinical features in a 16-year-old girl affected with CGL (CG 600.5). The left and right panels show anterior and posterior view, respectively, demonstrating near total absence of subcutaneous fat from the face, neck, trunk, arms and legs, extreme muscular appearance, acromegaloid features, umbilical hernia and severe acanthosis nigricans in the axillae, trunk and popliteal fosse.

\section{Subjects and Methods}

\section{Families}

All studies were approved by the appropriate Institutional Review Boards and informed consent was obtained from all subjects. We recruited 17 pedigrees with CGL. Clinical features of affected subjects from 6 families have been previously published $(4,19-23)$. Pedigrees CG 100 and 3100 are Turkish; CG 300, 700, 2900 and 3300 are Caucasian, CG 400, 800, 900, 3000 and 3200 are African, CG 3500 is Hispanic, CG 1100 is Taiwanese and CG 1300 is Chinese from North America; CG 600 is African and CG 2800 is Caucasian from the United Kingdom; and CG 1000 is from Pakistan. The phenotype was classified as affected or unaffected. This determination was made on the basis of history and physical examination and by review of their medical records. Furthermore, telephone interviews were conducted and photographs of affected subjects were inspected, where available. Generalized lack of body fat and extreme muscularity from birth was the essential criterion for diagnosis. Additional supportive criteria included the presence of acanthosis nigricans, umbilical hernia, acromegaloid features, hirsutism, early-onset diabetes mellitus, hypertriglyceridemia and hyperinsulinemia. In 6 patients, whole body MRI studies provided confirmation of a characteristic body fat distribution previously published by us (4). All phenotypes were assigned prospectively before beginning genotyping.

\section{Genotyping}

DNA was extracted from buffy coats or lymphoblastoid cell lines using standard protocols. Genome wide linkage analysis spanning all autosomes and subsequent genotyping of markers flanking locations suggestive of linkage was performed using fluorescently labeled primers from the Weber Version 8 panel of polymerase chain reaction (PCR)-amplifiable polymorphic short tandem repeats (STRs) (Research Genetics, Huntsville, AL) as described (24) using an ABI 377 DNA Sequencer equipped with GeneScan 2.1 and GENOTYPER softwares (Applied Biosystems). Marker order and distances between them were obtained from the database at the Center for Medical Genetics (www.marshmed.org/genetics).

\section{Linkage analyses}

The PEDMANAGER (Whitehead Institute for Biomedical Research, www.genome.wi.mit.edu) software was used to check for non-Mendelian inheritance of alleles and to estimate allele frequencies (25). The CHROMPIC option of CRIMAP was used to identify double recombinants. An autosomal recessive inheritance and a disease gene frequency of 1 in 1,000 were assumed for conducting the linkage analyses. The penetrance and phenocopy rates were varied between $90-100 \%$ and $0-1 \%$, respectively. Parametric analyses, heterogeneity testing and multipoint analyses were performed with GENEHUNTER (26). Two-point lod scores were obtained with the FASTLINK version of LINKAGE $(27,28)$.

\section{Results}

An initial genome-wide linkage scan with 386 polymorphic STRs, spaced an average of $10 \mathrm{cM}$ apart, was undertaken. Seven informative pedigrees (CG 100,400,600,800, 900, 1000 and 1300) that included 5 males and 9 females with CGL and 21 unaffected subjects were analyzed (Fig. 2). Preliminary evidence for linkage was obtained with 5 regions on chromosomes 1p, 1q, 9q, 10q and 13q where two-point lod scores exceeded 1.0. Further exploration with markers from additional loci known to map in these regions provided further evidence of linkage to chromosome $9 \mathrm{q} 34$ but did not support linkage to the other regions. Homozygosity was also noted among 2 affected subjects from the consanguineous pedigree CG 1000 . However, the other consanguineous pedigree, CG 100 , did not appear to be linked to $9 \mathrm{q} 34$ since multipoint lod scores for this pedigree were negative across the region (data not shown). 

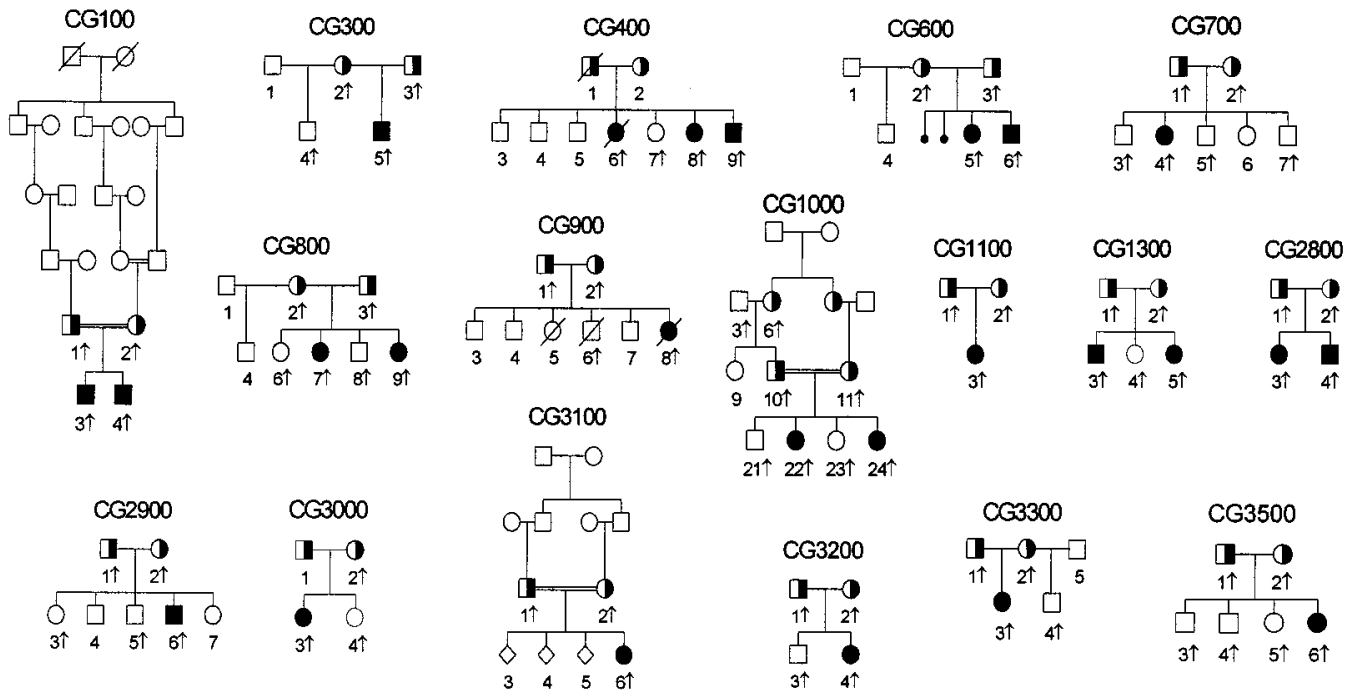

Fig. 2. CGL pedigrees. Individuals for whom DNA was available are indicated by $\uparrow$. Affected individuals are shown as filled black symbols, unaffected subjects as unfilled symbols, and parents of affected individuals are shown as half-filled symbols (obligate heterozygotes). Consanguinity is shown as double horizontal lines. Deceased individuals are indicated by a diagonal line, $\diamond$ indicates sex unknown, and $\bullet$ indicates miscarriages.

Subsequently, 10 additional pedigrees (CG 300,700, 1100, $2800,2900,3000,3100,3200,3300$ and 3500) were genotyped for markers spanning a $41 \mathrm{cM}$ region of chromosome $9 q 34$ (Fig. 2). Table 1 shows the total pairwise lod score data for loci which provided the highest lod scores. The maximum total two-point lod score, summed over all 17 families was 3.6 at recombination fraction $\left(\theta_{\max }\right)=0.05$ with D9S1818 (100\% penetrance and $0 \%$ phenocopy rate). The admixture test was significant when tested against multipoint lod score data, with the proportion of linked families, $\alpha=0.73$. In addition to CG 100 , pedigree CG 2800 did not appear to be

TABLE 1. Pairwise total lod scores between polymorphic microsatellite containing loci on chromosome 9q34 and CGL

\begin{tabular}{llllllll}
\hline & \multicolumn{9}{c}{$\theta$} & & \\
\cline { 2 - 7 } Locus & 0.00 & 0.01 & 0.05 & 0.1 & 0.2 & $Z \max$ & $\theta \max$ \\
\hline$D 9 S 1793$ & $-\infty$ & 1.85 & 3.13 & 3.18 & 2.35 & 3.23 & 0.08 \\
D9S1818 & $-\infty$ & 2.97 & 3.64 & 3.35 & 2.28 & 3.64 & 0.05 \\
$D 9 S 1826$ & $-\infty$ & 0.76 & 1.66 & 1.67 & 1.20 & 1.71 & 0.07 \\
$D 9 S 158$ & $-\infty$ & 1.59 & 2.43 & 2.34 & 1.64 & 2.44 & 0.06 \\
\hline
\end{tabular}

All 17 pedigrees were analyzed. Lod scores were generated with a recessive mode of inheritance, a penetrance of $100 \%$ and no phenotypic a phenocopy rate of 0 . Locus order from centromere to q telomere is D9S1793, D9S1818, D9S1826 and D9S158. linked to the critical region (all multipoint lod scores for this pedigree were negative). There were, however, no phenotypic or clinical differences between the affected subjects from the 2 unlinked and other pedigrees. The maximum total two-point lod score excluding the unlinked pedigrees was 4.1 with $D 9 S 1793$ and D9S1818 at $\theta_{\max }=0.04$ and 0.03 , respectively. Using equal allele frequencies and those from the CEPH database revealed maximum total two-point lod scores of 3.64 and 3.82 , respectively at $\theta_{\max }=0.05$, with $D 9 S 1818$. Assuming reduced penetrance of $90 \%$ and a phenocopy rate of $1 \%$ made little difference to the maximum lod score or the placement of the CGL locus (data not shown).

Multipoint analysis over a $41 \mathrm{cM}$ region of chromosome $9 q 34$ assuming genetic homogeneity in all 17 pedigrees revealed negative lod scores (LOD17) over much of the region and reached a maximum of 2.0 between loci $D 9 S 1818$ and D9S1826. Assuming genetic heterogeneity, a maximum lod score (HLOD17) of 3.6 was attained (Fig. 3). Multipoint analysis excluding the 2 unlinked families yielded a maximum lod score (LOD15) of 5.4 between loci D9S1818 and D9S1826 (Fig. 3).

Within the linked $9 \mathrm{q} 34$ region are genes for the human Surfeit locus 1 (SURF1), progesterone-associated endometrial protein (PAEP), carboxyl ester lipase (CEL), fucosyltransferase 7 (FUT7), ribosomal protein 7A (RPL7A), type $\mathrm{V}$ collagen, alpha 1 (COL5A1), ficolin 
(collagen/fibrinogen domain-containing) 1 (FCN1) and $\mathrm{RXR} \alpha$. Of these, the gene for $\mathrm{RXR} \alpha$ is a strong candidate gene for CGL because of its role in adipocyte differentiation. Mutational analysis is underway to determine if $R X R A$ is defective in affected subjects from the pedigrees linked to
$9 \mathrm{q} 34$. In the 2 pedigrees that were unlinked to the $9 \mathrm{q} 34$ region (CG 100 and 2800), direct sequencing of PPAR $\gamma$ exons in affected members failed to reveal any alterations in this gene (results not shown).

a

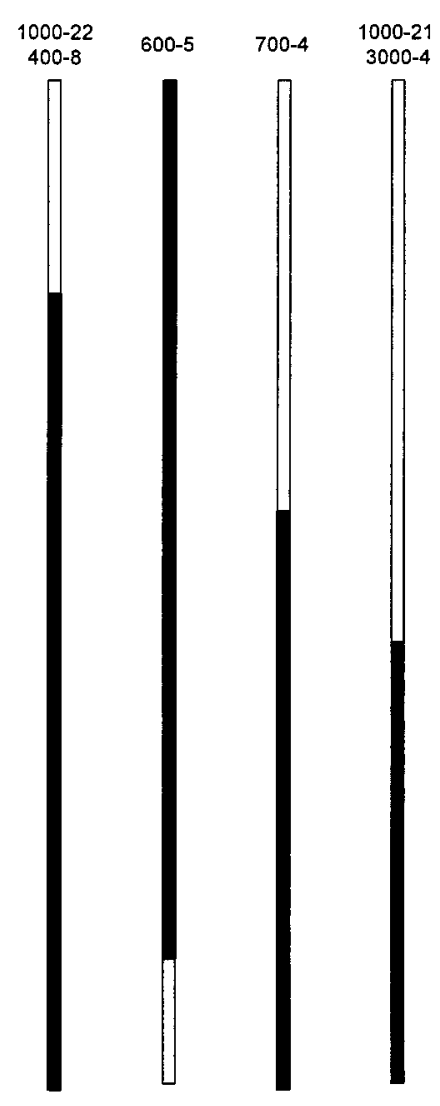

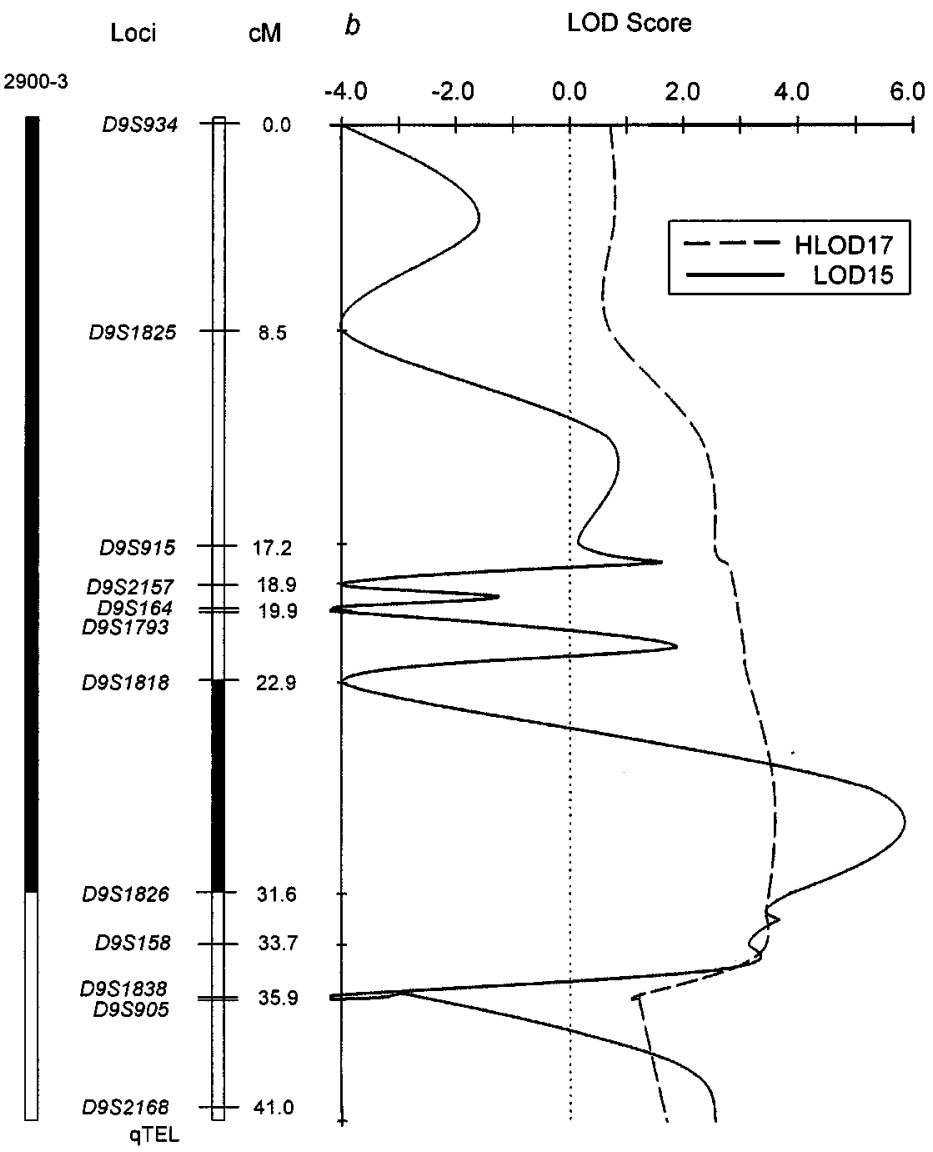

Fig. 3. Localization of a gene for CGL. $a$, Recombinants from the linked pedigrees that define the critical region. Filled portion of the vertical bar indicates the interval likely to harbor the CGLI gene based on the haplotypes (The individuals are designated as shown in Fig. 2). Recombinants localize the defective gene to $8.7 \mathrm{cM}$ region between loci $D 9 S 1818$ and $D 9 S 1826$, shown as the filled region of the locus bar. The disease-associated haplotypes differed for each family. The location of the $q$ telomere is indicated by "qTEL". $\boldsymbol{b}$, Multipoint analysis: The position of D9S934 was arbitrarily set at 0.0 -cM and the positions of the other loci were fixed according to the sex-averaged distance determined with CEPH pedigree data. The total distance between D9S934 and D9S2168 is $41 \mathrm{cM}$. Multipoint lod scores on the $\mathrm{x}$-axis are plotted against chromosome 9 loci on the $\mathrm{y}$-axis. HLOD17 (interrupted line) shows the results of the LOD score analysis under the heterogeneity hypothesis, when all families were considered. LOD15 (solid, uninterrupted line) was obtained under the hypothesis of homogeneity in 15 pedigrees, excluding the 2 unlinked pedigrees (CG 100 and 2800). 


\section{Discussion}

Our data provide evidence for at least two CGL loci: CGL1 on human chromosome 9q34, within a $8.7 \mathrm{cM}$ interval spanned by the loci $D 9 S 1818$ and $D 9 S 1826$ and one other, CGL2, as yet unmapped. Cloning of CGL genes will lead to a better understanding of the primary pathogenetic mechanisms involved in the loss of adipose tissue and may provide insights into embryonic differentiation of preadipocytes into metabolically active or mechanical adipocytes. Furthermore, it may lead to elucidation of mechanisms by which adipose tissue disorders such as lipodystrophies and common forms of regional adiposity lead to insulin resistance, diabetes mellitus and dyslipidemia.

\section{Acknowledgments}

We thank the families for their participation; Drs. Naseem Jafri, David Finegold, Mark Lipson, David Schwartz, Jonathan Darling and Timothy Cox for referring their families; Travis Petricek and Angela Osborn for technical help and illustrations; and the nursing and dietetic services of the General Clinical Research Center for patient care support. This work was supported by the National Institutes of Health grants R01-DK54387 and M01-RR00633 and the Southwestern Medical Foundation.

\section{References}

1. Berardinelli W. 1954 An undiagnosed endocrinometabolic syndrome: report of 2 cases. J Clin Endocrinol Metab. 14:193-204.

2. Seip M. 1959 Lipodystrophy and gigantism with associated endocrine manifestations: a new diencephalic syndrome? Acta Paediatr. 48:555-574.

3. Seip M, Trygstad O. 1996 Generalized lipodystrophy, congenital and acquired (lipoatrophy). Acta Paediatr (Suppl). 413:2-28.

4. Garg A, Fleckenstein JL, Peshock RM, Grundy SM. 1992 Peculiar distribution of adipose tissue in patients with congenital generalized lipodystrophy. J Clin Endocrinol Metab. 75:358-61.

5. Pardini VC, Victoria I, M., Rocha SM, et al. 1998 Leptin levels, ß-cell function, and insulin sensitivity in families with congenital and acquired generalized lipoatropic diabetes. J Clin Endocrinol Metab. 83:503-508.

6. Sovik O, Vestergaard H, Trygstad O, Pedersen O. 1996 Studies of insulin resistance in congenital generalized lipodystrophy. Acta Paediatr (Suppl). 413:29-37.

7. Westvik J. 1996 Radiological features in generalized lipodystrophy. Acta Paediatr (Suppl). 413:44-51

8. Fleckenstein JL, Garg A, Bonte FJ, Vuitch MF, Peshock RM. 1992 The skeleton in congenital generalized lipodystrophy: evaluation using whole-body radiographic surveys, magnetic resonance imaging and technetium-99m bone scintigraphy. Skel Radiol. 21:381-386

9. Bjornstad P, Foerster A, Thlen H. 1996 Cardiac findings in generalized lipodystrophy. Acta Paediatr (Suppl). 413:39-43.

10. Case Records of the Massachusetts General Hospital. 1975 Weekly clinicopathologic exercises. Case 1-1975. N Engl J Med. 292:35-41.

11. Chandalia M, Garg A, Vuitch F, Nizzi F. 1995 Postmortem findings in congenital generalized lipodystrophy. J Clin Endocrinol Metab. 80:30773081.

12. Moller DE, Cohen O, Yamaguchi Y, et al. 1994 Prevalence of mutations in the insulin receptor gene in subjects with features of the type A syndrome of insulin resistance. Diabetes. 43:247-55.

13. Vigouroux C, Khallouf E, Bourut C, et al. 1997 Genetic exclusion of 14 candidate genes in lipoatropic diabetes using linkage analysis in 10 consanguineous families. J Clin Endocrinol Metab. 82:3438-3444.

14. Vigouroux C, Fajas L, Khallouf E, et al. 1998 Human peroxisome proliferator-activated receptor- $\gamma 2$ : genetic mapping, identification of a variant in the coding sequence, and exclusion as the gene responsible for lipoatrophic diabetes. Diabetes. 47:490-492.

15. Silver K, Walston J, Plotnick L, Taylor SI, Kahn CR, Shuldiner AR. 1997 Molecular scanning of $\beta$-3-adrenergic receptor gene in total congenital lipoatrophic diabetes mellitus. J Clin Endocrinol Metab. 82:3395-3398.

16. Okazawa H, Mori H, Tamori $\mathbf{Y}$, et al. 1997 No coding mutations are detected in the peroxisome proliferator-activated receptor- $\gamma$ gene in Japanese patients with lipoatrophic diabetes. Diabetes. 46:1904-1906.

17. Shimomura I, Hammer RE, Richardson JA, et al. 1998 Insulin resistance and diabetes mellitus in transgenic mice expressing nuclear SREBP-1c in adipose tissue: model for congenital generalized lipodystrophy. Genes Dev. 12:3182-94.

18. Moitra J, Mason MM, Olive M, et al. 1998 Life without white fat: a transgenic mouse. Genes Dev. 12:3168-3181.

19. Jafri N, Zaidi Z. 1992 Congenital generalized lipodystrophy. J Pakistan Med Assoc. 42:74-6.

20. Gurakan F, Kocak N, Yuce A. 1995 Congenital Generalized Lipodystrophy: Berardinelli Syndrome. Turkish J Pediatr. 37:241-246.

21. Huseman C, Johanson A, Varma M, Blizzard RM. 1978 Congenital lipodystrophy: an endocrine study in three siblings. I. Disorders of carbohydrate metabolism. J Pediatr. 93:221-226.

22. Huseman C, Johanson A, Varma M, Blizzard R. 1979 Congenital lipodystrophy II association with polycystic ovarian disease. J Pediatr. 95:72-74.

23. Senior B, Gellis SS. 1964 The syndromes of total lipodystrophy and of partial lipodystrophy. Pediatrics. 33:593-612.

24. Peters JM, Barnes R, Bennett L, Gitomer WM, Bowcock AM, Garg A. 1998 Localization of the gene for familial partial lipodystrophy (Dunnigan variety) to chromosome 1q21-22. Nat Genet. 18:292-295.

25. Kruglyak L, Daly MJ, Reeve-Daly MP, Lander ES. 1996 Parametric and nomparametric linkage analysis: a unified multipoint approach. Am J Hum Genet. 58:1347-1363.

26. Lander E, Green P. 1996 Construction of multilocus genetic linkage maps in humans. Proc Natl Acad Sci USA. 84:2363-2367.

27. Lathrop GM, Lalouel JM, Julier C, Ott J. 1984 Strategies for multilocus linkage analysis in humans. Proc Natl Acad Sci USA. 81:34433446.

28. Schaffer AA, Gupta SK, Shriram K, Cottingham RWJ. 1994 Avoiding recomputation in linkage analysis. Hum Hered. 44:225-237. 